Fixed Point Theory, 23(2022), No. 1, 35-44

DOI: $10.24193 /$ fpt-ro.2022.1.03

http://www.math.ubbcluj.ro/ nodeacj/sfptcj.html

\title{
GENERALIZED METRIC SPACES AND SOME RELATED FIXED POINT THEOREMS
}

\author{
ABDERRAHIM EL ADRAOUI*, MUSTAPHA KABIL** AND SAMIH LAZAIZ*** \\ *Laboratory of Analysis Modeling and Simulation, \\ Faculty of Sciences Ben M'sick, \\ Hassan II University of Casablanca, Morocco. \\ (Corresponding author) \\ E-mail: a.adraoui@live.fr \\ ** Laboratory Mathematics, Computer Science and Applications, \\ Faculty of Sciences and Technologies Mohammedia, \\ Hassan II University of Casablanca, Morocco \\ E-mail: mustapha.kabil@fstm.ac.ma \\ ***ENSAM Casablanca, Hassan II University, Casablanca, Morocco \\ E-mail: samih.lazaiz@gmail.com
}

\begin{abstract}
In this paper, we study the existence of fixed point for relational endomorphisms. This class of mappings generalizes that of order and edge preserving mappings on posets and graphs respectively. As an application, we give a DeMarr-Type result for a family of Banach operator pairs in a binary relational system.

Key Words and Phrases: Binary relation, fixed point, generalized metric spaces, nonexpansive mapping, normal structure, relational endomorphisms.

2020 Mathematics Subject Classification: 37C25, 06A75, 47H09, 47H10, 08A02.
\end{abstract}

Acknowledgement. The authors would like to thank Maurice Pouzet with whom we had fruitful discussions regarding this work. Also, we are pleased to thank the referees of this paper for thoughtful suggestions and numerous corrections.

\section{REFERENCES}

[1] L. Belluce, W.A. Kirk, E. Steiner, Normal structure in Banach spaces, Pacific Journal of Mathematics, 26(1968), no. 3, 433-440.

[2] J. Chen, Z. Li, Common fixed-points for Banach operator pairs in best approximation, Journal of Mathematical Analysis and Applications, 336(2007), no. 2, 1466-1475.

[3] R. DeMarr, Common fixed points for commuting contraction mappings, Pacific Journal of Mathematics, 13(1963), no. 4, 1139-1141.

[4] M. Deza, E. Deza, Encyclopedia of Distances, In Encyclopedia of Distances, Springer, 2009.

[5] A.A. Gillespie, B.B. Williams, Fixed point theorem for non-expansive mappings on Banach spaces with uniformly normal structure, Applicable Analysis, 9(1979), no. 2, 121-124.

[6] M. Jawhari, D. Misane, M. Pouzet, Retracts: graphs and ordered sets from the metric point of view, Contemp. Math., 57(1986), 175-226. 
[7] M. Kabil, M. Pouzet, Injective envelope of graphs and transition systems, Discrete Mathematics, 192(1998), no. 1-3, 145-186.

[8] M. Kabil, M. Pouzet, Injective envelopes of transition systems and Ferrers languages, RAIROTheor. Inf. Appl., 54(2020).

[9] M. Kabil, M. Pouzet, I.G. Rosenberg, Free monoids and generalized metric spaces, European Journal of Combinatorics, 80(2019), 339-360.

[10] M.A. Khamsi, Generalized metric spaces: a survey, Journal of Fixed Point Theory and Applications, 17(2015), no. 3, 455-475.

[11] M.A. Khamsi, M. Pouzet, A fixed point theorem for commuting families of relational homomorphisms. applications to metric spaces, ordered sets and oriented graphs, Topology and its Applications, 273(2020), 106970.

[12] Y. Kijima, W. Takahashi, A fixed point theorem for nonexpansive mappings in metric space, Kodai Mathematical Seminar Reports, 21(1969), 326-330.

[13] W.A. Kirk, A fixed point theorem for mappings which do not increase distances, The American Mathematical Monthly, 72(1965), no. 9, 1004-1006.

[14] W.A. Kirk, An abstract fixed point theorem for nonexpansive mappings, Proceedings of the American Mathematical Society, 82(1981), no. 4, 640-642.

[15] W.A. Kirk, Nonexpansive mappings in metric and Banach spaces, Rendiconti del Seminario Matematico e Fisico di Milano, 51(1981), no. 1, 133-144.

[16] W.A. Kirk, N. Shahzad, Fixed Point Theory in Distance Spaces, Springer, 2014.

[17] J.P. Penot, Fixed point theorems without convexity, Mémoires de la Société Mathématique de France, 60(1979), 129-152.

[18] A. Tarski, A lattice-theoretical fixpoint theorem and its applications, Pacific Journal of Mathematics, 5(1955), no. 2, 285-309.

Received: April 22, 2020; Accepted: April 2, 2021. 